\title{
Inducing Angiogenesis, A Key Step in Cancer Vascularization, and Treatment Approaches
}

\author{
Harman Saman ${ }^{1,2, *}$, Syed Shadab Raza ${ }^{3}$, Shahab Uddin ${ }^{4}$ and Kakil Rasul 5 \\ 1 Barts Cancer Institute, Queen Mary University of London, London E1 4NS, UK \\ 2 Department of Medicine, Hazm Maubrairek Hospital, Ar-Rayyan, PO Box 305, Qatar \\ 3 Department of Stem Cell Biology and Regenerative Medicine, ERA University, Lucknow 226003, India; \\ Drshadab@erauniversit.In \\ 4 Translational Research Institute, Academic Health System, Hamad Medical Corporation, Doha 3050, Qatar; \\ Skhan34@hamad.qa \\ 5 National Cancer Care and Research, Hamad Medical Corporation, Doha 3050, Qatar; Krasul@hamad.qa \\ * Correspondence: HSaman@hamad.qa or h.saman@smd19.qmul.ac.uk; Tel.: +97-466506781
}

\begin{abstract}
Angiogenesis is a term that describes the formation of new blood and lymphatic vessels from a pre-existing vasculature. This allows tumour cells to acquire sustenance in the form of nutrients and oxygen and the ability to evacuate metabolic waste. As one of the hallmarks of cancer, angiogenesis has been studied extensively in animal and human models to enable better understanding of cancer biology and the development of new anti-cancer treatments. Angiogenesis plays a crucial role in the process of tumour genesis, because solid tumour need a blood supply if they are to grow beyond a few millimeters in size. On the other hand, there is growing evidence that some solid tumour exploit existing normal blood supply and do not require a new vessel formation to grow and to undergo metastasis. This review of the literature will present the current understanding of this intricate process and the latest advances in the use of angiogenesis-targeting therapies in the fight against cancer.
\end{abstract}

Keywords: angiogenesis; cancer; VEGF; anticancer

\section{Introduction}

Under physiological conditions, angiogenesis is a highly regulated process. It plays crucial roles in embryogenesis, wound healing and the menstrual cycle [1]. Angiogenesis is also seen in nonmalignant pathologies such as diabetic retinopathy, ischaemic diseases and autoimmune conditions such as connective tissue diseases and psoriasis [1].

In addition to providing nutrients and oxygen to the tumour and the removal of metabolic waste, new vessel formation also enables cancer cells to metastasize and proliferate to distant sites through entry into the newly formed blood and lymphatic system and subsequent extravasation [2]. A lack of adequate blood supply, on the other hand, could halt tumour growth, and might even lead to tumour shrinkage and sometimes cancer cell death [3]. Previous studies demonstrated that, in the absence of angiogenesis, tumours could grow to a maximum of $1-2 \mathrm{~mm}^{3}$ in diameter before they stopped growing and died, whilst some tumour cells could grow beyond $2 \mathrm{~mm}^{3}$ in size in angiogenesis-rich cell culture (4). The continued growth of cancer cells in angiogenesis-rich cell culture is explained by reproducing physiological properties in a three-dimensional cell culture model that provides controlled fluid perfusion that permits the regulation of oxygen intake, promoting a circulatory environment that is controlled by computer hardware [4]. 


\section{Angiogenesis in Normal Tissue}

The structure of the blood vessels depends on their size; small blood vessels are comprised of endothelial cells (EC), whereas in medium and large blood vessels, ECs are surrounded by pericytes (mural cells) [5]. In normal tissue, the process of neovascularization is tightly controlled. The process includes stepwise stages (Figure 1).

(I). Vasculogenic assembly, artery vein differentiation, lumen formation

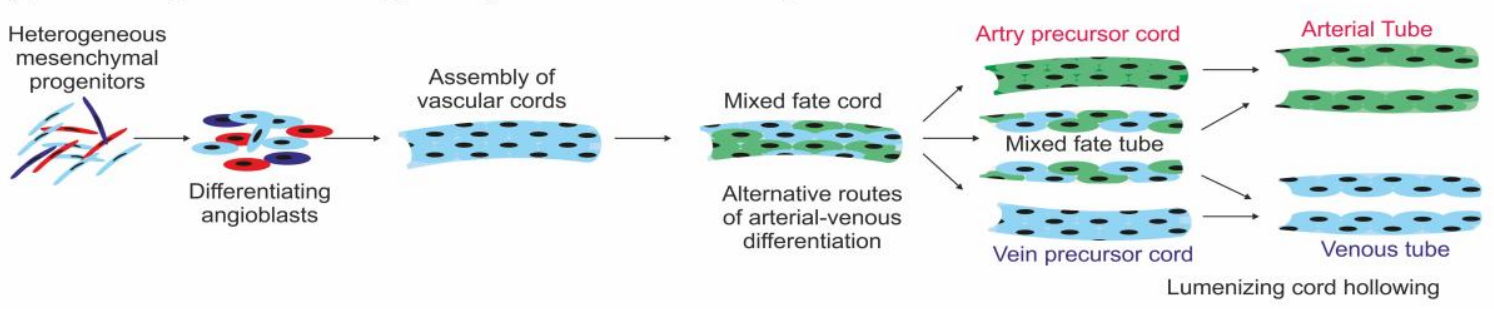

(II). Sprouting, guidance, branching, anastomoses, lumen formation

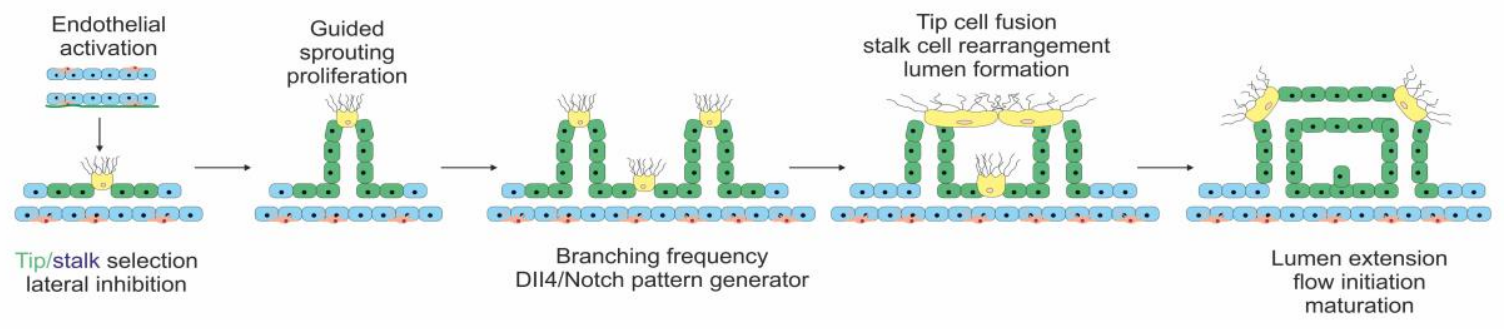

(III). Vascular remodeling, regression
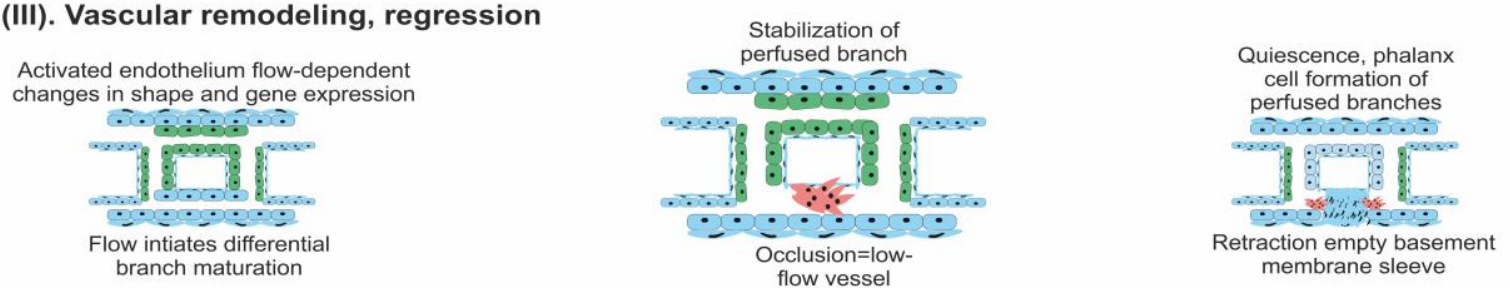

Figure 1. Steps of angiogenesis: (I) - Endothelial cell (EC) differentiated from angioblasts. (II) sprouting, guidance, branching, anastomoses, lumen formation. (III) - vascular remodeling from a primitive (left box) towards a stabilized and mature vascular plexus (right box).

After this strictly controlled vessel formation, the normal vasculature becomes largely quiescent [5]. Angiogenesis is controlled by several growth factor stimulators and inhibitors. Angiogenic (stimulatory) growth factors include Fibroblast Growth Factor, Granulocyte Colony-Stimulating Factor, Interleukin-8, Transforming Growth Factors alpha and beta and Vascular Endothelial Growth Factor. Angiogenic inhibitors include Angiostatin, Interferons (alpha, beta and gamma), Endostatin, Interleukin-12 and retinoids [5]. Inhibitory factors are present within the extra-cellular matrix (ECM). At a molecular level, angiogenesis is normally controlled by a family of small none-coding RNA molecules that are collectively called angiomiRs . AngiomiRs are comprised of pro-angiogenic miRs and anti-angiogenic miRs (Table 1) [6]. A well-studied angiomiRs is miR-200b, which belongs to the miR-200 family [7]. miR-200b has antiangiogenic effects. Its expression is transiently turned down when new vessel formation is required, for example during wound-healing. Once the physiological demand subsides, miR-200b is expressed again to stop angiogenesis as a measure of tight control on new vessel formation. The downregulation of miR-200b in response to tissue hypoxia triggers epithelial to mesenchymal transition and modulates endothelial cell migration which result in new vessel formation [8]. There is evidence that the dysregulation of iR-200b contributes to oncogenesis and metastasis in some cancers, such as breast cancer [9].

Table 1. AngiomiR are none-coding RNAs that play an important role in angiogenesis in normal tissue, through their expression or silencing depending on physiological demand. The dysregulation 
of miR-200b is detected in some cancers. Different types of AngiomiR have specific effects on angiogenesis.

\begin{tabular}{|c|c|c|}
\hline AngiomiR & Molecular function & Reference \\
\hline $\begin{array}{l}\text { miR-15b, miR-16, miR- } \\
\text { 20a, miR-20b }\end{array}$ & $\begin{array}{c}\text { Have no known functions. They might contribute in } \\
\text { regulation of VEGF. }\end{array}$ & [10] \\
\hline miR-21, miR-31 & Triggers mobilisation of EC. & [11] \\
\hline miR-17-92 & $\begin{array}{l}\text { Dysregulation of miR-17-92 } \\
\text { in cancer cells promote growth. }\end{array}$ & [12] \\
\hline miR-130a & Induces angiogenesis by supressing GAX and HOXA5 & [13] \\
\hline miR-296 & $\begin{array}{l}\text { Animal studies showed that by acting on HGS, miR-296 } \\
\text { stimulate angiogenesis. }\end{array}$ & [14] \\
\hline miR-320 & $\begin{array}{l}\text { Suppression of miR-320 in diabetic cells trigger } \\
\text { angiogenesis by stimulating EC proliferation. }\end{array}$ & [15] \\
\hline miR-210 & $\begin{array}{l}\text { In hypoxic cell culture, miR-210 promote EC proliferation } \\
\text { and survival. }\end{array}$ & [16] \\
\hline miR-378 & $\begin{array}{l}\begin{array}{l}\text { Support tumour growth by improving vascularisation via } \\
\text { angiogenesis. }\end{array}\end{array}$ & [17] \\
\hline
\end{tabular}

\section{Angiogenesis in Cancer, A Literature Review}

In cancer, a switch to angiogenesis seems to be an imbalance between stimulatory and inhibitory factors that leads to a pro-angiogenic state [18]. This results from a state of a relatively poorly bloodsupplied hyperplasia converted to an uncontrollable new vessel formation that ultimately causes malignant tumour progression. Researchers have investigated the molecular basis of pro- and inhibitory pathways with the view of better understanding oncogenesis and the development of anticancer treatment. The flip side of angiogenesis is poor tumour blood supply. Poor tumour blood supply is one of the postulated mechanisms of resistance to chemotherapy, due to the failure of an adequate delivery of cytotoxic drugs to the tumour site [19]. For example, for decades the five year overall survival of pancreatic cancer has not exceeded 5\%, despite extensive research [20]. One explanation for this is that pancreatic cancer tissue is surrounded by dens stromal tissue that hinders the delivery of anticancer therapies. In contrast to antiangiogenetic treatment, vascular promotion therapy is investigated to promote tumour blood supply to facilitate the better delivery of cytotoxic drugs to the target tissue [20].

\section{Pro- and Anti-Angiogenic Factors}

Judah Folkman coined the phrase tumour angiogenesis and studied this process extensively [18]. He led the discovery of the first angiogenic factors. These factors trigger neovascularization through inducing angiogenesis switch [21]. As seen in Figure 2, tumour overgrowth is believed to be halted through maintaining an equilibrium between pro- and anti-angiogenesis factors, leading to a state of tumour dormancy $[18,21]$. 


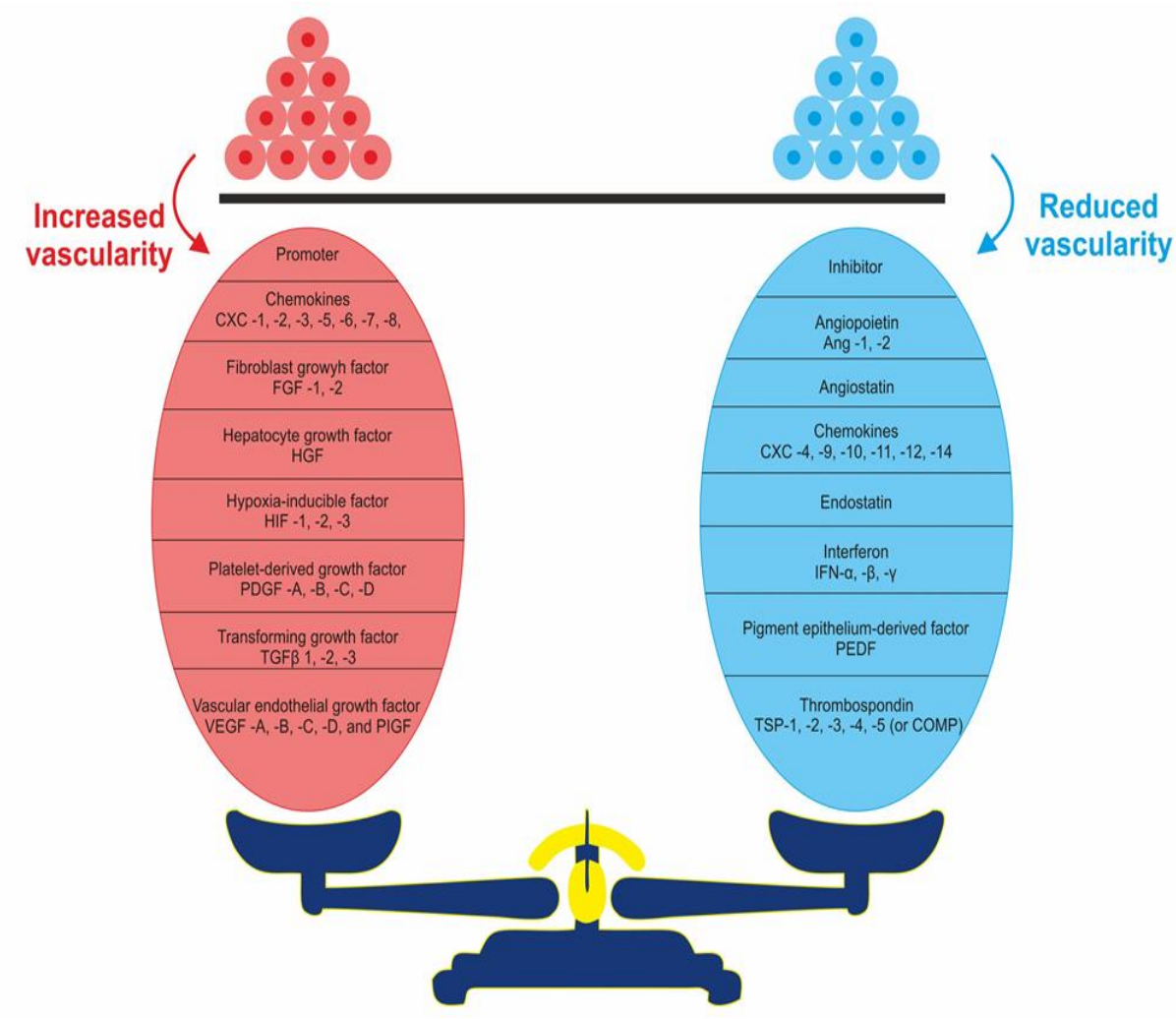

Figure 2. Maintaining homeostasis results from an equilibrium between promotors and inhibitors of angiogenesis.

Disturbance to this equilibrium results in increased angiogenesis, and thus uncontrollable tumour overgrowth [22]. Several angiogenic factors have been described. Of those, vascular endothelial growth factor A (VEGF-A) is a major regulator of angiogenesis both under normal conditions and in disease state [11]. VEGF-A belongs to family of gene factors that also encompasses VEGF-B, VEGF-C, VEGF-D, VEGF E and placenta growth factor (PIGF). These growth factors have different levels of specificity and different affinities to tyrosine kinase receptors (VEGFR) 1,-2 and -3 [22]. The binding of VEGF-A to VEGFR 2 (predominantly found on EC of blood vessels) leads to angiogenesis, whereas VEGF-C and D preferentially bind to VEGFR-3, expressed predominantly on lymphatic EC, resulting in the proliferation of lymphatic vessels [23]. In cancer, the role of VEGF exceeds angiogenesis through a complex autocrine and paracrine signaling pathway; VEGF plays an important role in promoting the cancer stem cells' functionality and the initiation of tumour [24]. The upregulation of VEGF initiates tumourigenesis by contributing to the activation of epithelialmesenchymal transition (EMT) [25]. EMT represents a key event in the process of new vessel formation. [26]. This because EMT leads to a loss of cell polarity and dramatic cytoskeletal changes, which lead to increased cell motility and loss of cells to cell adhesion by the loss of E-cadherin and ZO-1. The last two markers are associated with epithelial cells. EMT also results in the production of several proteolytic enzymes, including matrix metalloproteases and serine proteases that degrade the extracellular matrix (ECM). Several pathways involved in EMT support endothelial cell (EC) survival and proliferation [26]. These pathways invlove complex interactions between the cell membrane, ECM and intracellular regulatory signalling pathways. The resulting phenotypical changes caused by EMT promote cancer cell invasion of basement membrane, and eventually cancer cell metastasis [27].

Moreover, in hypoxic tumour, tumour-associated macrophages (TAMs), known for their protumour functions, secrete VEGF. VEGF interacts with key immune cells in the tumour microenvironment (TME), namely CD4+ forkhead box protein P3 (FOXP3) + regulatory T cells, which a strong suppressor of anticancer immunity. VEGF is able to attract these regulatory $\mathrm{T}$ cells to the TME using the chemoattractant neuropilin 1 (NRP1). Animal studies showed that removing NRP1 was 
associated with increased infiltration of TME with antitumoural CD8 T cells, with a reduction in tumour growth (14). Fibroblasts, that are present in abundance in TME and known to support tumour growth, also secrete VEGF. VEGF, in turn, stimulates fibronectin fibril assembly; the latter has a potent protumour effect within the TME [28].

Other angiogenesis promotors include platelet-derived growth factor (PDGF)-B and C and fibroblast growth factor (FGF)-1 and -2 [29]. Both groups of factors exert their effect, EC proliferation and migration, once they bind to their respective receptors on blood vessels' EC.

As seen in Figure 3, Tie1 and Tie2 are two signaling pathways that encompass the interaction between angiopoietins, tyrosine kinases (TK), VEGF and their receptors [29].

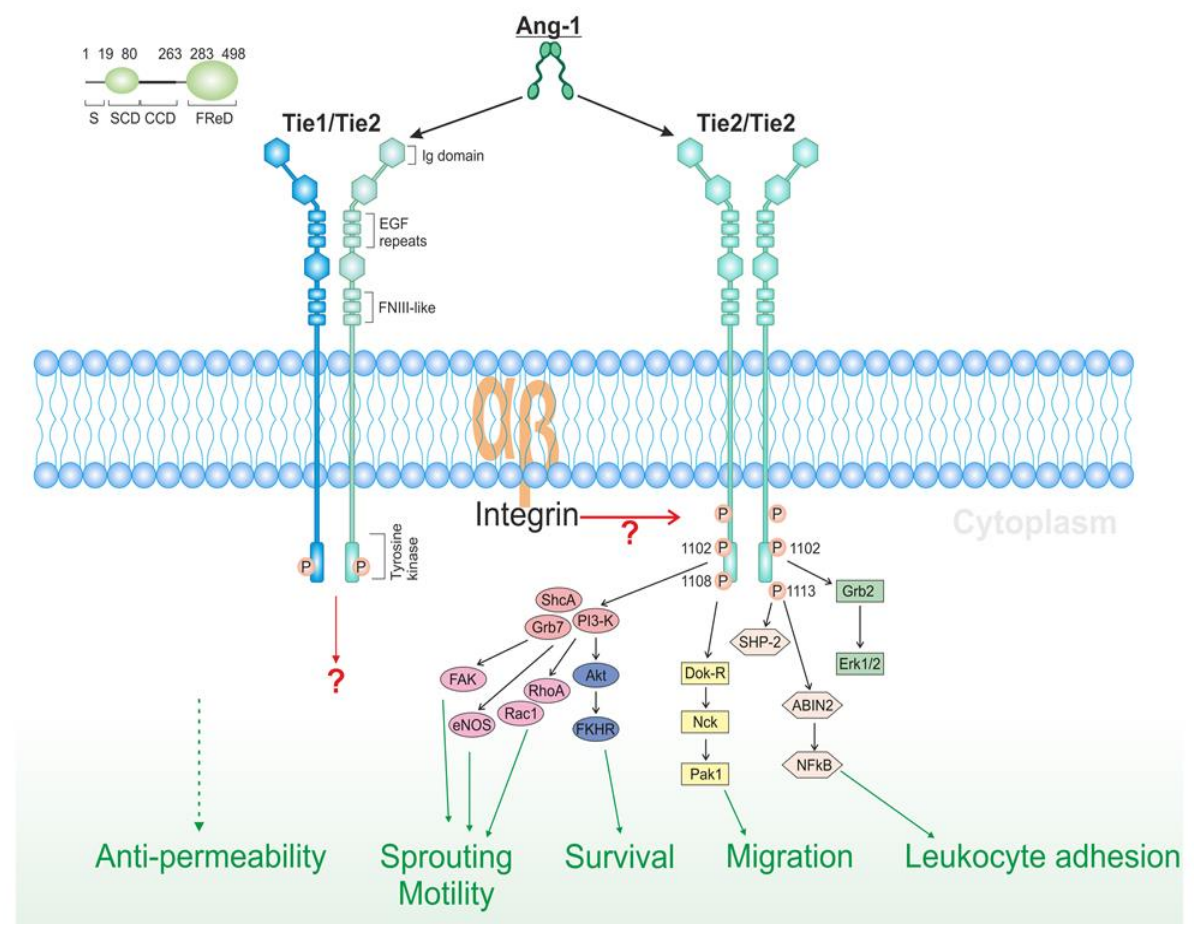

Figure 3. Ang1 and Ang2 bind to Tie2 with similar affinities; however, whereas Ang1 is an agonist, the ability of Ang2 to activate Tie2 appears to depend on the cell type and context. The activation of the Tie2 pathway results in the inhibition of apoptosis, cell survival and migration.

Other important regulators of angiogenesis are angiopoietins. Angiopoietins interact with Tie-2 TK receptor found on EC. Through cooperating with other angiogenesis factors, angiopoietins modulate the activity of the EC [29,30]. Angiopoietin-1 (Ang-1) and angiopoietin-2 (Ang-2) can form dimers, trimers and tetramers. Angiopoietin-1 can form higher-order multimers through its super clustering domain. It is believed that not all these structures bind with the TK receptor; the only activators of these receptors are at the tetramer level or higher [30].

Other promotors of angiogenesis include a wide range of polypeptides, metabolites and hormones that contribute to new blood vessels' formation in both physiological and disease state [30]. On the other hand, there is a wide range of antiangiogenetic factors that oppose the function of the promotors. Constituents and proteolytic fragments of the extra-cellular matrix (ECM) and the basement membrane represent potent angiogenesis inhibitors [31]. A well-studied angiogenesis inhibitor is thrombospondin-1 (TSP1), which is a large glycoprotein present in ECM [31]. Another matrix-derived angiogenesis inhibitor is a proteolytic product of collagen XVIII called endostatin [32]. Interferon-alpha and -beta and angiostatin, a cleavage product of plasmin, are other examples of angiogenesis inhibitors [33].

The activities of both angiogenesis promoters and inhibitors are regulated through a complex interaction of different pathways. The proangiogenic imbalance often occurs at the gene level due to the activation of oncogenes or inactivation of tumour suppressor genes, all the way to cell environmental factors such as hypoxia, hypoglycaemia, cellular nutrient deficiency and metabolic 
acidosis [34]. As part of multistage tumourigenesis, angiogenic switch arises from an imbalance between pro- and inhibitors of angiogenesis activity and level; this imbalance is driven from the tumour cells and the inflammatory cells that infiltrate the tumour [35]. The next section will focus on the mechanisms behind angiogenic switches in cancer and the different pathways involved.

\section{Angiogenic Switch}

In a seminal paper, Judah Folkman, Doug Hanahan and colleagues presented angiogenic switch in a transgenic Rip1Tag2 mouse module of pancreatic beta-cell carcinogenesis, during the progression from hyperplasia to heavily vascularised cancer [36]. Rip1Tag2 mice express the Simian Virus 40 large $\mathrm{T}$ antigen oncoprotein under the control of the rat insulin promoter. This leads to the overexpression of oncogene in pancreatic beta-cells of the islets of Langerhans, resulting in the development of beta-cell tumour. The study of Rip1Tag2 mice showed the phases of tumour genesis, from normal cells to hyperplasia, and adenoma to invasive carcinoma. VEGF-A was shown to be the main driver of EC proliferation, migration and tube formation, all essential components of angiogenesis [36]. Mice that overexpressed human VEGF-A165 in pancreatic beta-cells had angiogenesis at an early stage of tumourigenesis [37](21). In contrast, inhibiting VEGF-A resulted in suppressing angiogenic switch and tumour growth [38,39]. Different techniques were used to inhibit VEGF-A, such as chemical inhibitors of VEGFR signaling or genetically depleting VEGF-A in betacells $[39,40]$. Figure 4 is a schematic representation of angiogenic switch in transgenic mice; it shows progression from dormant hyperplasia to growing hyper-vascularized tumours as the result of angiogenesis.

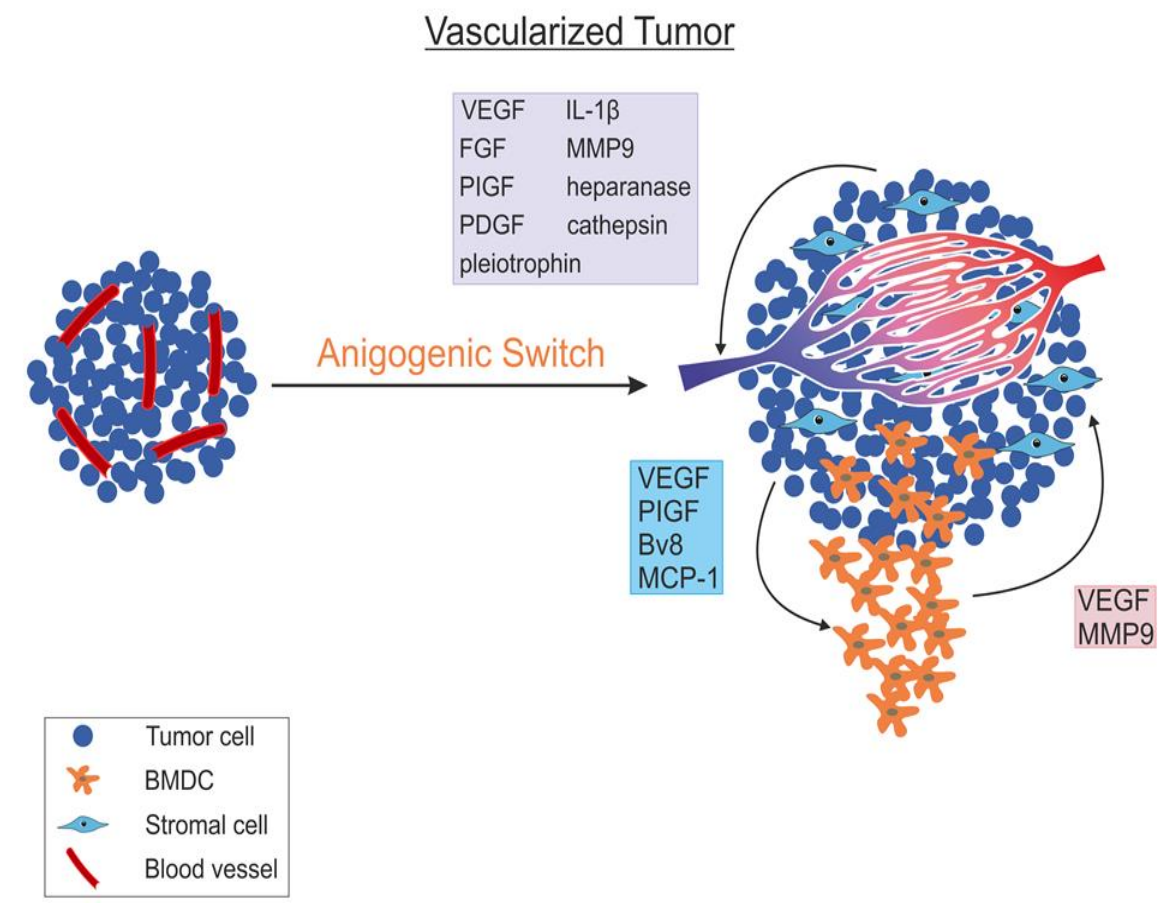

Figure 4. Angiogenic switch in transgenic mouse, showing progression from hyperplasia to hypervascularised tumour. The pro-angiogenic factors and proteases secreted by the tumour cells themselves (green box) and the cells of the immune system recruited to the tumour site (pink box), and the factors secreted by the tumour cells to recruit inflammatory cells (blue box).

Another important element of angiogenic switch is stromal cells of tumour microenvironment [41]. Through chemotaxis, cancer cells recruit innate immune cells. The immune cells contribute to angiogenesis via secreting pro-angiogenic factors. Using paracrine stimulation, tumour-associated macrophages (TAM) partake in the modulation of angiogenesis and tumour progression [42]. The 
cytokine/chemokine component of the tumour microenvironment determines the function of TAM. This function is either the M1 state of macrophages, which is an anticancer, or the M2 state, which suppresses immunity and promotes tumourigenesis via secreting pro-angiogenic cytokines and VEGF-A [43].

Endothelial progenitor cells (EPC), are also believed to play a role in angiogenesis [44] . Tumoursecreted factors recruit EPC from bone marrow to the tumour site to contribute to angiogenesis [45]. However, the exact role of EPC in angiogenesis remains to be fully understood [44,45]. Studies of mouse models of breast cancer have shown that myeloid progenitors differentiated to EC, leading to neovascularization [46]. This is further evidence of the role of the immune cells in promoting angiogenesis.

Importantly, not all tumours rely on new blood vessel formation to survive and grow [47], and therefore the angiogenic switch might never occur. Some tumours exploit the existing blood supply through a process named vessel co-option to support their growth and to enable metastasis. Vessel co-option has been observed in a number of tumours such as non-small cell lung cancer (NSCLC), glioblastoma and hepatocellular carcinoma [48,49]. Cancer cells seem to grow along existing vessels and/or invade the connective tissue that is present between the vessels, allowing the cancer cells to incorporate to the existing normal vasculature to begin hijacking the blood supply [50,51]. There is evidence that vessel co-option promotes cancer cell motility and metastasis and tumour dormancy [52]. Moreover, some tumours such as NSCLC, use both angiogenesis and vessel co-option simultaneously or sequentially (in no particular order) to acquire blood supply and venous and lymphatic drainage [53]. Moreover, there is growing evidence that increased vascularity, often measured through microvascular density, caused by vessel co-option, is associated with higher tumour grade and higher risk of metastasis [54]. Interestingly, bone marrow appears to be an important site for vessel co-option in both primary and secondary bone malignancies which, in turn, might explain the development of tumour dormancy in bones and the higher rate of chemoresistance $[55,56]$.

In addition there is also evidence from preclinical studies that show that some tumors, such NSCLC and gliomas, never undergo angiogenic switch and rely only on vessel co-option [53,57]. In contrast, some tumors, for example hepatocellular carcinoma and liver metastases of the gastrointestinal tract, switch from using vessel co-option at early stages of tumourigenesis to angiogenesis at a later stage during tumour progression [58,59]. This progression from vessel cooption to angiogenesis is not an obligatory requirement of tumour progression and metastasis [60]. Moreover, preclinical and clinical studies showed that there are, at times, but not always, differences that exist between primary and secondary versions of of the same tumour in terms of their access to blood supply [61,62]. For example, when cells from angiogenic primary human breast tumors spread to the lung tissue, they switch to vessel co-option as a mode of accessing blood supply [62], which also functions as a resistant mechanism against antiangiogenic therapy [54].

\section{Tumour Vasculature Modulation as A Therapeutic Option}

Vascular Promotion Therapy

This approach is presumed to work though improving the delivery of cytotoxic agent(s) to the tumour (Figure 5). 


\title{
Vasculature Promoting Therapy
}

\author{
Producing less leaky blood vessels
}

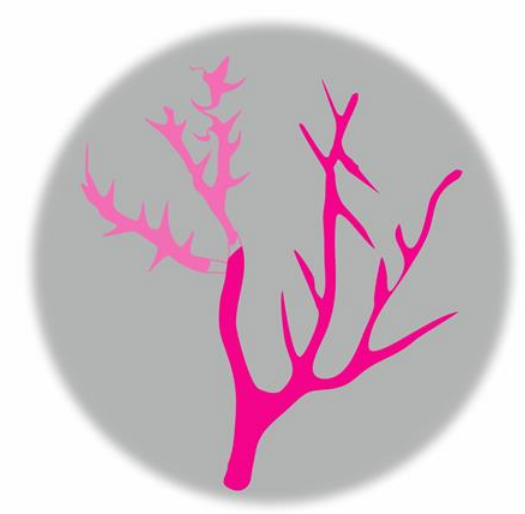

Increased $\mathrm{O}_{2}$ 个个

Figure 5. Promoting tumour blood supply to improve cytotoxic delivery to tumour. This approach might be particularly effective in tumours that are poorly supplied by blood, such as pancreatic cancer.

An example of this is the use of Cilengitide and Verapamil in conjunction with Gemcitabine or Cisplatin to treat pancreatic ductal adenocarcinoma [63]. In high doses, Cilengitide, a selective inhibitor of integrins, leads to inhibition of the FAK/SRC/AKT pathway, causing apoptosis in EC. This drug was originally developed as an antiangiogenic agent. However, in clinical trials, it showed no efficacy in the treatment of glioblastoma. A low dosing of Cilengitide was, however, observed to be associated with the promotion of tumour angiogenesis [64]. Verapamil, a calcium channel blocker, causes vasodilatation, hence the increased blood flow to tumour. Cilengitide and Verapamil, in addition to Gemcitabine administered in a xenograft tumour model, through various schedules, mimicking human dosing regimens, was studied in trials by Wong et al. [63].

The impact of the therapy on the tumour blood flow was assessed by flow cytometry, imaging techniques and the concentration of the drugs in vital organs, tumour, and blood levels. The studies showed increased functional (less leaky) vessel formation, leading to an improved tumour blood supply to both highly and poorly vascularized tumors. This effect translated into tumour regression and improved survival in vivo models. The authors showed that vascular promotion increased the cell uptake of Gemcitabine with reduced side effects. The authors also argued that the promotion of vascularization improved the efficacy of Cisplatin due to better tumour blood perfusion, which improved cytotoxic delivery, leading to tumour regression in mice model. Future studies should deal with the impact of this approach in different tumour sites and their secondaries, address the wide variations in tumour behavior caused by intratumor heterogeneity and focus on the potential complications of promoting neovascularization, such as the risk of significant/life threatening bleeding, and its safety in vascular diseases.

\section{Immune Modulation}

As mentioned, the infiltration of tumour microenvironment with immune cells, importantly TAM, is associated with pro-angiogenic factor secretions by these cells. Several experiments studied the inhibition of TAM function or their complete removal from the tumour microenvironment. A study showed that treating K14-HPV/E2 mice with Zoledronic acid (ZA), a bisphosphonate used for skeletal metastasis with anti-inflammatory and anti-osteoclast properties, resulted in the suppressed mobilization of VEGF-A and, consequently, the inhibition of angiogenesis and tumourigenesis [65]. Other studies showed that treatment with ZA in advanced solid tumors was associated with a 
reduction in VEGF-A plasma levels [66]. The inhibition of neutrophils and macrophages to reverse angiogenic switch has been tested in preclinical trials but not applied in clinical settings [67]. Other immune modulated strategies that have been studied include: inhibition of Cyclooxygenase-2 (COX2) expression by COX-2 inhibitors in pancreatic and cervical cancer [68] and Lenalidomide (an immunomodulatory drug) in advanced renal cancer [69], with benefits in phase two trials but no additional advantage in combination with standard cytotoxic protocols.

\section{Anti-Angiogenic Therapy}

The Food and Drug Administration (FDA) approved biological therapies in the form of tyrosine kinase inhibitors (TKIs), monoclonal antibodies and fusion peptides in non-small cell lung cancer, metastatic colorectal cancer, medullary thyroid cancer and renal cell cancer a [70]. More specifically, targeting VEGF has become an important approach to stop tumour growth (Figure 6), and part of the treatment protocol of several tumour primaries, notably colon, non-small cell lung and renal cell cancers [71]. Several studies showed that arteriol formation and tortuosity, as well as venous dilation, are increased through VEGF expression [72]. Cell culture injected with adenovirus expressing VEGF undergo the induction of mother vessels (MV) and stabilized MV from normal capillaries and venules. In contrast, the inhibition of VEGF is shown to cause veins and arterioles to have fewer cleavage planes. For example, Aflibercept, a decoy receptor that binds VEGF-A, induces the rapid collapse of mother vessels (MV) to glomeruloid microvascular proliferations (GMP). VEGF inhibition, by antiVEGF/VEGF receptor, is shown to restore vasculature within hours to normal microvessels by way of GMP [73]. GMP is believed to act as an intermediary step in MV reversion to normal microvessels after VEGF blockade [74].

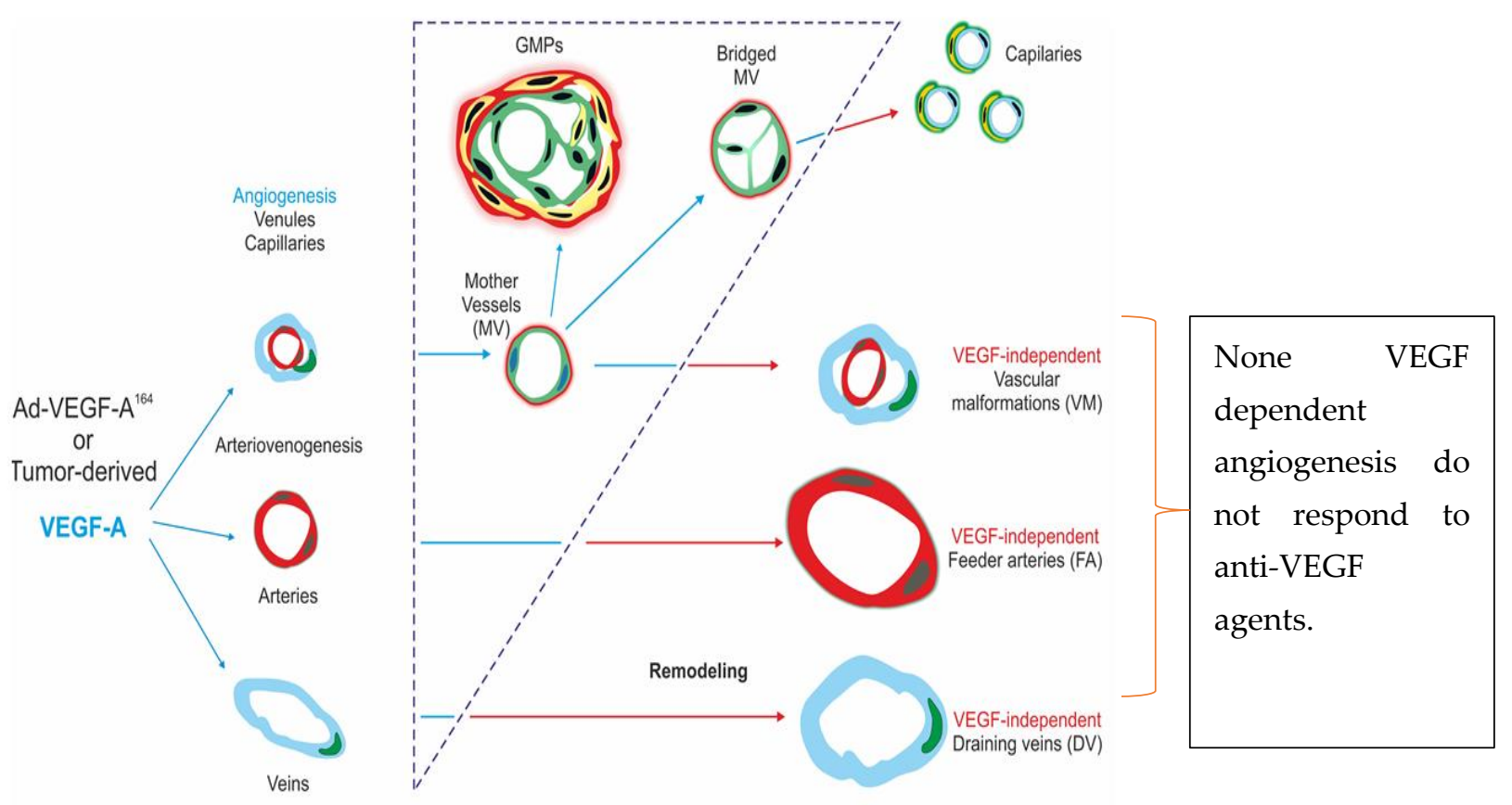

Figure 6. VEGF-A plays an important role in angiogenesis. The inhibition of VEGF-A prevents new vessel formation. VEGF-independent angiogenesis are not sensitive to the inhibition of VEGF-A.

Monoclonal antibodies such as Bevacizumab, which blocks the VEGF receptor, or small molecules such as Lapatinib, which inhibits TK downstream of VEGF, are examples of anti-VEGF treatment. Phase 1 trial of Bevacizumab showed that the drug was well tolerated and had good 
pharmacokinetic properties [75]. A phase 3 clinical trial of Bevacizumab in metastatic colorectal cancer (mCRC) showed a modest impact of 4 to 5 month improvement in overall survival (OS) in metastatic colon cancer [76]. In transgenic mouse models of non-squamous non-small cell lung cancer (nsNSCLC), Bevacizumab was shown to reduce the risk of brain metastasis, and therefore improve survival. This might translate into improved survival due to a reduction in the rate of brain metastases in patients with stage III nsNSCLC [77]. Despite prolonging the PFS of metastatic breast cancer, the FDA removed Bevacizumab from standard treatment protocol due to safety concerns [78].

Combining Bevacizumab with chemotherapy, in the first and second line settings of mCRC, improved OS [79]. The AVF2107g study showed an improvement in median survival from 15.6 to 20.3 months when combining Bevacizumab to irinotecan, bolus fluorouracil, and leucovorin, compared to placebo [76] in treatment-naïve mCRC patients. PFS, but not OS, was shown to improve in a randomized controlled trial of mCRC combining Bevacizumab with oxaliplatin-based chemotherapy as first-line treatment [80]. Another randomized controlled trial showed that adding Bevacizumab to fluorouracil and leucovorin improved PFS in patients with $\mathrm{mCRC}$ for whom firstline irinotecan was judged inappropriate due to their poor functional status [81]. The direct VEGFR2 antagonist, Ramucirumab, was approved in the treatment of advanced hepatocellular carcinoma (HCC) with high alpha-feto protein after progression to sorafenib [82]. Through binding to VEGF-B and placental growth factor, Ziv-aflibercept, a representative agent of the third type of angiogenesis inhibitor, composed of the extracellular domain of both VEGFR-1 and VEGFR-2 fused to the Fc region of IgG1, inhibits the pro-angiogenic effects of the VEGF/VEGFR signaling pathway [83]. Zivaflibercept, in combination with 5-fluorouracil, leucovorin and irinotecan (FOLFIRI) for mCRC, in patients resistant to or progressing after treatment with oxaliplatin, showed statistically significant improvements in PFS and OS[84].

Given the results of animal trials, this modest benefit of anti-VEGF-A/VEGFR therapy against human cancers has been relatively disappointing. One explanation for this modest effectiveness is that most cancer patients are elderly, frail and cannot tolerate high doses, in contrast to relatively healthy tumour-bearing mice that can be given higher doses [85]. Another possible reason is that tumour hypoxemia resulting from anti-VEGF-A/VEGFR therapy lead to the over-expression of matrix components that bind and sequester VEGF-A, rendering anti-VEGF drugs ineffective [86]. Hypoxia also might stimulate cancer cells to secrete other pro-angiogenic factors such as FGF, PDGFB, PDGF-C, HGF, EGF, IL-8, IL-6, Ang-2, SDF1a, PDGF-C, CXCL6 and others, as well as their receptors $[85,86]$. Mobilisation from bone marrow to the tumour site of vascular progenitor cells and proangiogenic myelocytes are other mechanisms that might be responsible for the limited effectiveness of anti-VEGF-A/VEGFR therapy [87]. Another hindrance to anti-angiogenesis therapy is that the blood supply to the tumour is reduced, and this would lead to the impairment of the delivery of chemotherapy agents to the tumour, hence reducing their cytotoxic effects. Antiangiogenic treatment creates a hypoxic tumour microenvironment, which results in the tumour cells becoming more "aggressive" and promotes "escaping" of the tumour cells from the hypoxic environment to distant, normo-oxic, sites, i.e., metastasis [88]. Other mechanisms of therapy resistance involve the recruitment of pro-growth cells and molecules to the TME by the cancer cells as the result of tumour hypoxia, such as tumour-associated macrophages [89], tumour-associated fibroblasts (TAFs) [90], Tie2 ${ }^{+}$monocytes [91], myeloid cells [92], pro-angiogenic bone-marrowderived cells including $\mathrm{CD}_{11} \mathrm{~b}^{+} \mathrm{Gr}^{+}$and the overexpression of alternative angiogenic signaling molecules [93], including a fibroblast growth factor-2 [94], interleukin-8 (IL-8) [95], IL-17 [96], and angiopoietin 2 [97].

Vessels' co-option as a mechanism to attain blood supply by cancer cells is another resistant mechanism to anti-angiogenic treatment. Preclinical models demonstrated a switch from angiogenesis to vessel co-option during anti-angiogenic treatment $[98,99]$. The escaping antiangiogenic agents' effect using vessel co-option is seen across a range of cancer types. For example, the modest response of glioma to bevacizumab is shown, in preclinical studies and clinical case reports, to be due to vessel co-option [100]. This could be intrinsic resistance or acquired during treatment with bevacizumab due to the switch from angiogenesis to the vessel co-option $[101,102]$. 
This switch from angiogenesis to the vessel co-option is also observed during the treatment of breast cancer with anti-angiogenic therapy. Pulmonary metastasis from breast cancer is shown to use the lung parenchymal blood supply for their survival and growth, which explains their resistance to antiangiogenic therapy [61]. In addition, preclinical trials showed that after an initial response of xenograft model of hepatocellular carcinoma to sorafenib (a multi-kinase inhibitor with antiangiogenic properties), the tumour progressed within a month due to the large-scale co-option of sinusoidal and portal tract vessels [54]. Moreover, several studies showed that resistance to antiangiogenic therapy in metastatic colorectal carcinoma (CRC) to the liver is likely secondary to the CRC cells co-option of pre-existing liver vessels; this can occur in the context of both intrinsic and acquired resistance [60].

\section{Novel and Future Approaches to Modify Angiogenesis as Anti-Cancer Option}

Targeting angiogenesis has shown limited effectiveness to date, but affirms Folkman's postulations. This limited success is likely caused by the heterogeneity of blood vessels, as some vessels are susceptible, whilst others are resistant, to the inhibition of VEGF/VEGFR. Furthermore, genomic instability would enable cancer cells to bypass the VEGF/VEGFR axis and stimulate new blood vessel growth using alternative signaling pathways. Future therapy should focus on targeting molecules, as well as VEGF, that are present on large blood vessels' EC lining. Targeting large vessels could stop the blood perfusion to the entire mass of the tumour, hence this would enhance the pruning of microvessels that are sensitive to the inhibition of VEGF/VEGFR. This concept was tested and supported by the findings of a study that utilised photodynamic energy to thrombose and subsequently blocked the main arteries and draining veins of a mouse ear tumour [103].

Another novel strategy is the use of nano-particles to deliver specific anti-angiogenic agents [104]. For example, endostatin, a protein that was extracted for the first time in 1996 from murine hemagioendothelioma (EOMA) cell culture medium [32]. Endostatin has a potent anti-angiogenic effect. The exact molecular anti-angiogenic mechanism(s) of endostatin are not fully understood and subject to investigation. In vitro and vivo studies showed that endostatins induce endothelial cell apoptosis, and suppress its proliferation and migration via a complex network of signaling [105]. However, there are important challenges in the clinical application of endostatin related to the chemical nature of this protein. These challenges include the short half-life and instability of the protein in vivo [106], the requirement of administering high volumes of endostatin to exert their antiangiogenic effects, which in itself is associated with significant practical and cost implications [107], as well as technological challenges related to manufacturing a correctly folded and soluble protein to ensure adequate bioactivity within the tumour cells [108]. To overcome these challenges, nanotechnology has been utilized to manufacture nanoparticles as transporters of this protein [109]. Cancer cells are shown to readily uptake nano-particles, and therefore the anti-tumoural activity of endostatin is enhanced when delivered via nano-particles [110]. In addition, by adding nine amino acids to the N-terminal of recombinant human endostain, endostar is produced. Endostar is a more stable molecular bioengineered form of endostatin. This is because endostar is better at resisting degradation by proteolytic enzymes and more stable during temperature changes [111].

Two independent studies by Chen et al. [112] and Hu et al. [113] have confirmed that endostar carried by nanoparticles have a better anticancer activity than the conventional delivery system because of the improved release and longer half-life of endostar in target tumour. Chen et al. studied prepared particulate carriers (nanoparticles and microspheres) of poly (DL-lactide-co-glycolide) (PLGA) and poly (ethylene glycol) (PEG)-modified PLGA (PEG-PLGA) to promote a better delivery and release of endostar, as the nano-transporter enables high encapsulation, rapidly release and the higher cancer intracellular bioavailability of endostar.

As explained above, the vessel co-option acts as an important mechanism of resistance to antiangiogenesis as well as an important source of blood supply that supports the growth of tumors. Therefore, the inhibition of the vessel co-option is the focus of many research groups, through targeting cell motility or adhesion pathways in tumour stroma. In in a mouse model of liver metastases, Frentzas et al. [60] showed that, by silencing the expression of actin-related protein 2/3 
(ARP2/3), a protein complex involved in actin-mediated cell motility, and the vessel co-option, can be inhibited. Interestingly, preclinical trials showed improved tumour control when VEGF and vessel co-options are inhibited simultaneously compared to the blocking of VEGF signalling alone [114]. Another novel approach that has been tested in mouse models of brain-metastatic breast cancer and showed some promising results, is the inhibition of the adhesion of cancer cells to pre-existing blood vessels to block vessel co-option through inhibition of L1 Cell Adhesion Molecule(L1CAM) or the cell adhesion receptor $\beta 1$ integrin [115]. Moreover, pre-clinical models of glioma, and metastases to the liver, lymph nodes or lungs that are vessel co-option-dependent, showed that blocking both the angiopoietin and VEGF pathways was more effective compared to the inhibition of VEGF alone $[116,117]$. The exact role of angiopoietin in the recruitment or maintenance of co-opted tumour vessels is not fully understood [118]. However, a phase 2 clinical trial of angiopoietin inhibition with and without bevacizumab in recurrent glioblastoma did not show any improvement in progression free survival (PFS) [118].

\section{Conclusion}

Excessive, insufficient or abnormal angiogenesis contributes to tumour survival, growth invasion and metastasis. Targeting single angiogenic (pro or inhibitory) molecules showed promising results in animal trials, but has been of limited success in human cancer. To date, despite their modest impact, anti VEGF continues to be one of the treatment lines of several solid malignancies. Nevertheless, it is believed that antiangiogenic monotherapy aiming at single molecule activity is insufficient to combat the myriad of angiogenic factors produced by cancer cells and its microenvironment and this would explain, at least partly, the modest effect of anti VEGF strategies. Future challenges include a detailed understanding of the many angio-modulating pathways in a more integrated manner to identify more holistic therapeutic approaches to improve survival rate in cancer patients.

Author Contributions: H.S. designing of manuscript, literature review, compiled the data, wrote the manuscript and supervised this manuscript. S.S.R. help in designing figures, reading and editing. S.U. assisted in preparing the designing the manuscript and help in writing and reading the manuscript. K.R. help design of the manuscript and contributed in writing and reading manuscript. All authors read and approved the final manuscript.

Funding: This research received no external funding.

Acknowledgments: The authors are thankful to Qatar National Library for its support for open access.

Conflicts of Interest: The authors declare no conflict of interest.

$\begin{array}{ll}\text { Abbreviations } \\ \text { Ang } & \text { Angiopoietin } \\ \text { CRC } & \text { Colorectal Cancer } \\ \text { EC } & \text { Endothelial cells } \\ \text { ECM } & \text { Extra-cellular matrix } \\ \text { EPC } & \text { Endothelial progenitor cells } \\ \text { FGF } & \text { Fibroblast growth factor } \\ \text { FOLFIRI } & \text { Fluorouracil, Leucovorin and Irinotecan } \\ \text { FOXP3 } & \text { Forkhead box protein P3 } \\ \text { HCC } & \text { Hepatocellular Carcinoma } \\ \text { NSCLC } & \text { non-squamous Non-small Cell Lung Cancer } \\ \text { PDGF } & \text { Platelet-derived growth factor } \\ \text { PFS } & \text { Progression free survival } \\ \text { PIGF } & \text { Placenta growth factor } \\ \text { TAFs } & \text { Tumour associated fibroblasts } \\ \text { TK } & \text { Tyrosine kinases } \\ \text { TME } & \text { Tumour micro-environment } \\ \text { TSP1 } & \text { Thrombospondin1 } \\ \text { VEGF } & \text { Vascular endothelial growth factor } \\ \end{array}$




\section{References}

1. Suh, D.Y. Understanding angiogenesis and its clinical applications. Ann. Clin. Lab. Sci. 2000, 30, $227-238$.

2. Nishida, N.; Yano, H.; Nishida, T.; Kamura, T.; Kojiro, M. Angiogenesis in cancer. Vasc. Health Risk Manag. 2006, 2, 213-219, doi:10.2147/vhrm.2006.2.3.213.

3. Ravi, R.; Mookerjee, B.; Bhujwalla, Z.M.; Sutter, C.H.; Artemov, D.; Zeng, Q.; Dillehay, L.E.; Madan, A.; Semenza, G.L.; Bedi, A. Regulation of tumor angiogenesis by p53-induced degradation of hypoxiainducible factor 1alpha. Genes. Dev. 2000, 14, 34-44.

4. McCoy, R.J.; O'Brien, F.J. Influence of shear stress in perfusion bioreactor cultures for the development of three-dimensional bone tissue constructs: A review. Tissue. Eng. Part B Rev. 2010, 16, 587-601, doi:10.1089/ten.TEB.2010.0370.

5. Carmeliet, P. Angiogenesis in health and disease. Nat. Med. 2003, 9, 653-660, doi:10.1038/nm0603-653.

6. Kuehbacher, A.; Urbich, C.; Zeiher, A.M.; Dimmeler, S. Role of Dicer and Drosha for endothelial microRNA expression and angiogenesis. Circ. Res. 2007, 101, 59-68, doi:10.1161/CIRCRESAHA.107.153916.

7. Chan, Y.C.; Roy, S.; Khanna, S.; Sen, C.K. Downregulation of endothelial microRNA-200b supports cutaneous wound angiogenesis by desilencing GATA binding protein 2 and vascular endothelial growth factor receptor 2. Arterioscler. Thromb. Vasc. Biol. 2012, 32, 1372-1382, doi:10.1161/ATVBAHA.112.248583.

8. Chan, Y.C.; Khanna, S.; Roy, S.; Sen, C.K. miR-200b targets Ets-1 and is down-regulated by hypoxia to induce angiogenic response of endothelial cells. J. Biol. Chem. 2011, 286, 2047-2056, doi:10.1074/jbc.M110.158790.

9. Zheng, Q.; Cui, X.; Zhang, D.; Yang, Y.; Yan, X.; Liu, M.; Niang, B.; Aziz, F.; Liu, S.; Yan, Q.; et al. miR-200b inhibits proliferation and metastasis of breast cancer by targeting fucosyltransferase IV and alpha1,3fucosylated glycans. Oncogenesis 2017, 6, 358, doi:10.1038/oncsis.2017.58.

10. Hua, Z.; Lv, Q.; Ye, W.; Wong, C.K.; Cai, G.; Gu, D.; Ji, Y.; Zhao, C.; Wang, J.; Yang, B.B.; et al. MiRNAdirected regulation of VEGF and other angiogenic factors under hypoxia. PLoS ONE 2006, 1, 116, doi:10.1371/journal.pone.0000116.

11. Tsai, Y.H.; Wu, M.F.; Wu, Y.H.; Chang, S.J.; Lin, S.F.; Sharp, T.V.; Wang, H.W. The M type K15 protein of Kaposi's sarcoma-associated herpesvirus regulates microRNA expression via its SH2-binding motif to induce cell migration and invasion. J. Virol. 2009, 83, 622-632, doi:10.1128/JVI.00869-08.

12. Doganov, N.; Negentsov, N. Clinical trial of the laksafer preparation on patients following gynecological operations. Akush. Ginekol. 1989, 28, 47-51.

13. Chen, Y.; Gorski, D.H. Regulation of angiogenesis through a microRNA (miR-130a) that down-regulates antiangiogenic homeobox genes GAX and HOXA5. Blood 2008, 111, 1217-1226, doi:10.1182/blood-2007-07104133.

14. Wurdinger, T.; Tannous, B.A.; Saydam, O.; Skog, J.; Grau, S.; Soutschek, J.; Weissleder, R.; Breakefield, X.O.; Krichevsky, A.M. miR-296 regulates growth factor receptor overexpression in angiogenic endothelial cells. Cancer Cell 2008, 14, 382-393, doi:10.1016/j.ccr.2008.10.005.

15. Byatt, G.; Dalrymple-Alford, J.C. Both anteromedial and anteroventral thalamic lesions impair radial-maze learning in rats. Behav. Neurosci. 1996, 110, 1335-1348, doi:10.1037//0735-7044.110.6.1335.

16. Pulkkinen, K.; Malm, T.; Turunen, M.; Koistinaho, J.; Yla-Herttuala, S. Hypoxia induces microRNA miR210 in vitro and in vivo ephrin-A3 and neuronal pentraxin 1 are potentially regulated by miR-210. FEBS Lett. 2008, 582, 2397-2401, doi:10.1016/j.febslet.2008.05.048.

17. Ventura, A.; Young, A.G.; Winslow, M.M.; Lintault, L.; Meissner, A.; Erkeland, S.J.; Newman, J.; Bronson, R.T.; Crowley, D.; Stone, J.R.; et al. Targeted deletion reveals essential and overlapping functions of the miR-17 through 92 family of miRNA clusters. Cell 2008, 132, 875-886, doi:10.1016/j.cell.2008.02.019.

18. Baeriswyl, V.; Christofori, G. The angiogenic switch in carcinogenesis. Semin. Cancer Biol. 2009, 19, 329-337, doi:10.1016/j.semcancer.2009.05.003.

19. Saggar, J.K.; Yu, M.; Tan, Q.; Tannock, I.F. The tumor microenvironment and strategies to improve drug distribution. Front. Oncol. 2013, 3, 154, doi:10.3389/fonc.2013.00154.

20. Bridges, E.; Harris, A.L. Vascular-promoting therapy reduced tumor growth and progression by improving chemotherapy efficacy. Cancer Cell 2015, 27, 7-9, doi:10.1016/j.ccell.2014.12.009.

21. Hanahan, D.; Weinberg, R.A. Retrospective: Judah Folkman (1933-2008). Science 2008, 319, 1055, doi:10.1126/science.1156080. 
22. Ferrara, N.; Gerber, H.P.; LeCouter, J. The biology of VEGF and its receptors. Nat. Med. 2003, 9, 669-676, doi:10.1038/nm0603-669.

23. Kubo, H.; Fujiwara, T.; Jussila, L.; Hashi, H.; Ogawa, M.; Shimizu, K.; Awane, M.; Sakai, Y.; Takabayashi, A.; Alitalo, K.; et al. Involvement of vascular endothelial growth factor receptor-3 in maintenance of integrity of endothelial cell lining during tumor angiogenesis. Blood 2000, 96, 546-553.

24. Goel, H.L.; Mercurio, A.M. VEGF targets the tumour cell. Nat. Rev. Cancer 2013, 13, 871-882, doi:10.1038/nrc3627.

25. Fantozzi, A.; Gruber, D.C.; Pisarsky, L.; Heck, C.; Kunita, A.; Yilmaz, M.; Meyer-Schaller, N.; Cornille, K.; Hopfer, U.; Bentires-Alj, M.; et al. VEGF-mediated angiogenesis links EMT-induced cancer stemness to tumor initiation. Cancer Res. 2014, 74, 1566-1575, doi:10.1158/0008-5472.CAN-13-1641.

26. Ghersi, G. Roles of molecules involved in epithelial/mesenchymal transition during angiogenesis. Front. Biosci. 2008, 13, 2335-2355, doi:10.2741/2848.

27. Polyak, K.; Weinberg, R.A. Transitions between epithelial and mesenchymal states: Acquisition of malignant and stem cell traits. Nat. Rev. Cancer 2009, 9, 265-273, doi:10.1038/nrc2620.

28. Galdiero, M.R.; Bonavita, E.; Barajon, I.; Garlanda, C.; Mantovani, A.; Jaillon, S. Tumor associated macrophages and neutrophils in cancer. Immunobiology 2013, 218, 1402-1410, doi:10.1016/j.imbio.2013.06.003.

29. Friesel, R.E.; Maciag, T. Molecular mechanisms of angiogenesis: Fibroblast growth factor signal transduction. FASEB J. 1995, 9, 919-925, doi:10.1096/fasebj.9.10.7542215.

30. Augustin, H.G.; Koh, G.Y.; Thurston, G.; Alitalo, K. Control of vascular morphogenesis and homeostasis through the angiopoietin-Tie system. Nat. Rev. Mol. Cell Biol. 2009, 10, 165-177, doi:10.1038/nrm2639.

31. Good, D.J.; Polverini, P.J.; Rastinejad, F.; Le Beau, M.M.; Lemons, R.S.; Frazier, W.A.; Bouck, N.P. A tumor suppressor-dependent inhibitor of angiogenesis is immunologically and functionally indistinguishable from a fragment of thrombospondin. Proc. Natl. Acad. Sci. USA 1990, 87, 6624-6628, doi:10.1073/pnas.87.17.6624.

32. O'Reilly, M.S.; Boehm, T.; Shing, Y.; Fukai, N.; Vasios, G.; Lane, W.S.; Flynn, E.; Birkhead, J.R.; Olsen, B.R.; Folkman, J. Endostatin: An endogenous inhibitor of angiogenesis and tumor growth. Cell 1997, 88, 277-285, doi:10.1016/s0092-8674(00)81848-6.

33. O’Reilly, M.S.; Holmgren, L.; Shing, Y.; Chen, C.; Rosenthal, R.A.; Moses, M.; Lane, W.S.; Cao, Y.; Sage, E.H.; Folkman, J. Angiostatin: A novel angiogenesis inhibitor that mediates the suppression of metastases by a Lewis lung carcinoma. Cell 1994, 79, 315-328, doi:10.1016/0092-8674(94)90200-3.

34. Pugh, C.W.; Ratcliffe, P.J. Regulation of angiogenesis by hypoxia: Role of the HIF system. Nat. Med. 2003, 9, 677-684, doi:10.1038/nm0603-677.

35. North, S.; Moenner, M.; Bikfalvi, A. Recent developments in the regulation of the angiogenic switch by cellular stress factors in tumors. Cancer Lett. 2005, 218, 1-14, doi:10.1016/j.canlet.2004.08.007.

36. Folkman, J.; Watson, K.; Ingber, D.; Hanahan, D. Induction of angiogenesis during the transition from hyperplasia to neoplasia. Nature 1989, 339, 58-61, doi:10.1038/339058a0.

37. Gannon, G.; Mandriota, S.J.; Cui, L.; Baetens, D.; Pepper, M.S.; Christofori, G. Overexpression of vascular endothelial growth factor-A165 enhances tumor angiogenesis but not metastasis during beta-cell carcinogenesis. Cancer Res. 2002, 62, 603-608.

38. O’Reilly, T.; Lane, H.A.; Wood, J.M.; Schnell, C.; Littlewood-Evans, A.; Brueggen, J.; McSheehy, P.M. Everolimus and PTK/ZK show synergistic growth inhibition in the orthotopic BL16/BL6 murine melanoma model. Cancer Chemother. Pharmacol. 2011, 67, 193-200, doi:10.1007/s00280-010-1307-z.

39. Vajkoczy, P.; Menger, M.D.; Vollmar, B.; Schilling, L.; Schmiedek, P.; Hirth, K.P.; Ullrich, A.; Fong, T.A. Inhibition of tumor growth, angiogenesis, and microcirculation by the novel Flk-1 inhibitor SU5416 as assessed by intravital multi-fluorescence videomicroscopy. Neoplasia 1999, 1, 31-41, doi:10.1038/sj.neo.7900006.

40. Bergers, G.; Javaherian, K.; Lo, K.M.; Folkman, J.; Hanahan, D. Effects of angiogenesis inhibitors on multistage carcinogenesis in mice. Science 1999, 284, 808-812, doi:10.1126/science.284.5415.808.

41. Bergers, G.; Song, S. The role of pericytes in blood-vessel formation and maintenance. Neuro. Oncol. 2005, 7, 452-464, doi:10.1215/S1152851705000232.

42. Pollard, J.W. Tumour-educated macrophages promote tumour progression and metastasis. Nat. Rev. Cancer 2004, 4, 71-78, doi:10.1038/nrc1256. 
43. Zumsteg, A.; Christofori, G. Corrupt policemen: Inflammatory cells promote tumor angiogenesis. Curr. Opin. Oncol. 2009, 21, 60-70, doi:10.1097/CCO.0b013e32831bed7e.

44. Bertolini, F.; Shaked, Y.; Mancuso, P.; Kerbel, R.S. The multifaceted circulating endothelial cell in cancer: Towards marker and target identification. Nat. Rev. Cancer 2006, 6, 835-845, doi:10.1038/nrc1971.

45. Bailey, A.S.; Willenbring, H.; Jiang, S.; Anderson, D.A.; Schroeder, D.A.; Wong, M.H.; Grompe, M.; Fleming, W.H. Myeloid lineage progenitors give rise to vascular endothelium. Proc. Natl. Acad. Sci. USA 2006, 103, 13156-13161, doi:10.1073/pnas.0604203103.

46. Nolan, D.J.; Ciarrocchi, A.; Mellick, A.S.; Jaggi, J.S.; Bambino, K.; Gupta, S.; Heikamp, E.; McDevitt, M.R.; Scheinberg, D.A.; Benezra, R.; et al. Bone marrow-derived endothelial progenitor cells are a major determinant of nascent tumor neovascularization. Genes. Dev. 2007, 21, 1546-1558, doi:10.1101/gad.436307.

47. Kuczynski, E.A.; Vermeulen, P.B.; Pezzella, F.; Kerbel, R.S.; Reynolds, A.R. Vessel co-option in cancer. Nat. Rev. Clin. Oncol. 2019, 16, 469-493, doi:10.1038/s41571-019-0181-9.

48. Kurzrock, R.; Stewart, D.J. Exploring the Benefit/Risk Associated with Antiangiogenic Agents for the Treatment of Non-Small Cell Lung Cancer Patients. Clin. Cancer Res. 2017, 23, 1137-1148, doi:10.1158/10780432.CCR-16-1968.

49. Khasraw, M.; Ameratunga, M.; Grommes, C. Bevacizumab for the treatment of high-grade glioma: An update after phase III trials. Expert Opin. Biol. Ther. 2014, 14, 729-740, doi:10.1517/14712598.2014.898060.

50. Vasudev, N.S.; Reynolds, A.R. Anti-angiogenic therapy for cancer: Current progress, unresolved questions and future directions. Angiogenesis 2014, 17, 471-494, doi:10.1007/s10456-014-9420-y.

51. Leenders, W.P.; Kusters, B.; de Waal, R.M. Vessel co-option: How tumors obtain blood supply in the absence of sprouting angiogenesis. Endothelium 2002, 9, 83-87, doi:10.1080/10623320212006.

52. Winkler, F. Hostile takeover: How tumours hijack pre-existing vascular environments to thrive. J. Pathol. 2017, 242, 267-272, doi:10.1002/path.4904.

53. Szabo, V.; Bugyik, E.; Dezso, K.; Ecker, N.; Nagy, P.; Timar, J.; Tovari, J.; Laszlo, V.; Bridgeman, V.L.; Wan, E., et al. Mechanism of tumour vascularization in experimental lung metastases. J. Pathol. 2015, 235, 384396, doi:10.1002/path.4464.

54. Kuczynski, E.A.; Yin, M.; Bar-Zion, A.; Lee, C.R.; Butz, H.; Man, S.; Daley, F.; Vermeulen, P.B.; Yousef, G.M.; Foster, F.S.; et al. Co-option of Liver Vessels and Not Sprouting Angiogenesis Drives Acquired Sorafenib Resistance in Hepatocellular Carcinoma. J. Natl. Cancer Inst. 2016, 108, doi:10.1093/jnci/djw030.

55. Raymaekers, K.; Stegen, S.; van Gastel, N.; Carmeliet, G. The vasculature: A vessel for bone metastasis. Bonekey Rep. 2015, 4, 742, doi:10.1038/bonekey.2015.111.

56. Ghajar, C.M.; Peinado, H.; Mori, H.; Matei, I.R.; Evason, K.J.; Brazier, H.; Almeida, D.; Koller, A.; Hajjar, K.A.; Stainier, D.Y.; et al. The perivascular niche regulates breast tumour dormancy. Nat. Cell Biol. 2013, 15, 807-817, doi:10.1038/ncb2767.

57. Baker, G.J.; Yadav, V.N.; Motsch, S.; Koschmann, C.; Calinescu, A.A.; Mineharu, Y.; Camelo-Piragua, S.I.; Orringer, D.; Bannykh, S.; Nichols, W.S.; et al. Mechanisms of glioma formation: Iterative perivascular glioma growth and invasion leads to tumor progression, VEGF-independent vascularization, and resistance to antiangiogenic therapy. Neoplasia 2014, 16, 543-561, doi:10.1016/j.neo.2014.06.003.

58. Terayama, N.; Terada, T.; Nakanuma, Y. Histologic growth patterns of metastatic carcinomas of the liver. Jpn. J. Clin. Oncol. 1996, 26, 24-29, doi:10.1093/oxfordjournals.jjco.a023174.

59. Kanai, T.; Hirohashi, S.; Upton, M.P.; Noguchi, M.; Kishi, K.; Makuuchi, M.; Yamasaki, S.; Hasegawa, H.; Takayasu, K.; Moriyama, N.; et al. Pathology of small hepatocellular carcinoma. A proposal for a new gross classification. Cancer 1987, 60, 810-819, doi:10.1002/1097-0142(19870815)60:4<810::aidcncr2820600417>3.0.c0;2-1.

60. Frentzas, S.; Simoneau, E.; Bridgeman, V.L.; Vermeulen, P.B.; Foo, S.; Kostaras, E.; Nathan, M.; Wotherspoon, A.; Gao, Z.H.; Shi, Y.; et al. Vessel co-option mediates resistance to anti-angiogenic therapy in liver metastases. Nat. Med. 2016, 22, 1294-1302, doi:10.1038/nm.4197.

61. Bridgeman, V.L.; Vermeulen, P.B.; Foo, S.; Bilecz, A.; Daley, F.; Kostaras, E.; Nathan, M.R.; Wan, E.; Frentzas, S.; Schweiger, T.; et al. Vessel co-option is common in human lung metastases and mediates resistance to anti-angiogenic therapy in preclinical lung metastasis models. J. Pathol. 2017, 241, 362-374, doi:10.1002/path.4845.

62. Guerin, E.; Man, S.; Xu, P.; Kerbel, R.S. A model of postsurgical advanced metastatic breast cancer more accurately replicates the clinical efficacy of antiangiogenic drugs. Cancer Res. 2013, 73, 2743-2748, doi:10.1158/0008-5472.CAN-12-4183. 
63. Wong, P.P.; Demircioglu, F.; Ghazaly, E.; Alrawashdeh, W.; Stratford, M.R.; Scudamore, C.L.; Cereser, B.; Crnogorac-Jurcevic, T.; McDonald, S.; Elia, G.; et al. Dual-action combination therapy enhances angiogenesis while reducing tumor growth and spread. Cancer Cell 2015, 27, 123-137, doi:10.1016/j.ccell.2014.10.015.

64. Reynolds, A.R.; Hart, I.R.; Watson, A.R.; Welti, J.C.; Silva, R.G.; Robinson, S.D.; Da Violante, G.; Gourlaouen, M.; Salih, M.; Jones, M.C.; et al. Stimulation of tumor growth and angiogenesis by low concentrations of RGD-mimetic integrin inhibitors. Nat. Med. 2009, 15, 392-400, doi:10.1038/nm.1941.

65. Giraudo, E.; Inoue, M.; Hanahan, D. An amino-bisphosphonate targets MMP-9-expressing macrophages and angiogenesis to impair cervical carcinogenesis. J. Clin. Invest. 2004, 114, 623-633, doi:10.1172/JCI22087.

66. Santini, D.; Vincenzi, B.; Dicuonzo, G.; Avvisati, G.; Massacesi, C.; Battistoni, F.; Gavasci, M.; Rocci, L.; Tirindelli, M.C.; Altomare, V.; et al. Zoledronic acid induces significant and long-lasting modifications of circulating angiogenic factors in cancer patients. Clin. Cancer Res. 2003, 9, 2893-2897.

67. Nozawa, H.; Chiu, C.; Hanahan, D. Infiltrating neutrophils mediate the initial angiogenic switch in a mouse model of multistage carcinogenesis. Proc. Natl. Acad. Sci. USA 2006, 103, 12493-12498, doi:10.1073/pnas.0601807103.

68. Bertagnolli, M.M.; Eagle, C.J.; Zauber, A.G.; Redston, M.; Solomon, S.D.; Kim, K.; Tang, J.; Rosenstein, R.B.; Wittes, J.; Corle, D.; et al. Celecoxib for the prevention of sporadic colorectal adenomas. N. Engl. J. Med. 2006, 355, 873-884, doi:10.1056/NEJMoa061355.

69. Aragon-Ching, J.B.; Li, H.; Gardner, E.R.; Figg, W.D. Thalidomide analogues as anticancer drugs. Recent. Pat. Anticancer. Drug Discov. 2007, 2, 167-174, doi:10.2174/157489207780832478.

70. Al-Abd, A.M.; Alamoudi, A.J.; Abdel-Naim, A.B.; Neamatallah, T.A.; Ashour, O.M. Anti-angiogenic agents for the treatment of solid tumors: Potential pathways, therapy and current strategies - A review. J. Adv. Res. 2017, 8, 591-605, doi:10.1016/j.jare.2017.06.006.

71. Meadows, K.L.; Hurwitz, H.I. Anti-VEGF therapies in the clinic. Cold Spring Harb. Perspect. Med. 2012, 2, doi:10.1101/cshperspect.a006577.

72. Hartnett, M.E.; Martiniuk, D.; Byfield, G.; Geisen, P.; Zeng, G.; Bautch, V.L. Neutralizing VEGF decreases tortuosity and alters endothelial cell division orientation in arterioles and veins in a rat model of ROP: Relevance to plus disease. Invest. Ophthalmol. Vis. Sci. 2008, 49, 3107-3114, doi:10.1167/iovs.08-1780.

73. Goffin, J.R.; Straume, O.; Chappuis, P.O.; Brunet, J.S.; Begin, L.R.; Hamel, N.; Wong, N.; Akslen, L.A.; Foulkes, W.D. Glomeruloid microvascular proliferation is associated with p53 expression, germline BRCA1 mutations and an adverse outcome following breast cancer. Br. J. Cancer 2003, 89, 1031-1034, doi:10.1038/sj.bjc.6601195.

74. Sitohy, B.; Chang, S.; Sciuto, T.E.; Masse, E.; Shen, M.; Kang, P.M.; Jaminet, S.C.; Benjamin, L.E.; Bhatt, R.S.; Dvorak, A.M.; et al. Early Actions of Anti-Vascular Endothelial Growth Factor/Vascular Endothelial Growth Factor Receptor Drugs on Angiogenic Blood Vessels. Am. J. Pathol. 2017, 187, 2337-2347, doi:10.1016/j.ajpath.2017.06.010.

75. Gordon, M.S.; Margolin, K.; Talpaz, M.; Sledge, G.W., Jr.; Holmgren, E.; Benjamin, R.; Stalter, S.; Shak, S.; Adelman, D. Phase I safety and pharmacokinetic study of recombinant human anti-vascular endothelial growth factor in patients with advanced cancer. J. Clin. Oncol. 2001, 19, 843-850, doi:10.1200/JCO.2001.19.3.843.

76. Hurwitz, H.; Fehrenbacher, L.; Novotny, W.; Cartwright, T.; Hainsworth, J.; Heim, W.; Berlin, J.; Baron, A.; Griffing, S.; Holmgren, E.; et al. Bevacizumab plus irinotecan, fluorouracil, and leucovorin for metastatic colorectal cancer. N. Engl. J. Med. 2004, 350, 2335-2342, doi:10.1056/NEJMoa032691.

77. Ilhan-Mutlu, A.; Osswald, M.; Liao, Y.; Gommel, M.; Reck, M.; Miles, D.; Mariani, P.; Gianni, L.; Lutiger, B.; Nendel, V.; et al. Bevacizumab Prevents Brain Metastases Formation in Lung Adenocarcinoma. Mol. Cancer Ther. 2016, 15, 702-710, doi:10.1158/1535-7163.MCT-15-0582.

78. Montero, A.J.; Escobar, M.; Lopes, G.; Gluck, S.; Vogel, C. Bevacizumab in the treatment of metastatic breast cancer: Friend or foe? Curr. Oncol. Rep. 2012, 14, 1-11, doi:10.1007/s11912-011-0202-z.

79. Rosen, L.S.; Jacobs, I.A.; Burkes, R.L. Bevacizumab in Colorectal Cancer: Current Role in Treatment and the Potential of Biosimilars. Target. Oncol. 2017, 12, 599-610, doi:10.1007/s11523-017-0518-1.

80. Saltz, L.B.; Clarke, S.; Diaz-Rubio, E.; Scheithauer, W.; Figer, A.; Wong, R.; Koski, S.; Lichinitser, M.; Yang, T.S.; Rivera, F.; et al. Bevacizumab in combination with oxaliplatin-based chemotherapy as first-line therapy in metastatic colorectal cancer: A randomized phase III study. J. Clin. Oncol. 2008, 26, 2013-2019, doi:10.1200/JCO.2007.14.9930. 
81. Van Cutsem, E.; Cervantes, A.; Adam, R.; Sobrero, A.; Van Krieken, J.H.; Aderka, D.; Aranda Aguilar, E.; Bardelli, A.; Benson, A.; Bodoky, G.; et al. ESMO consensus guidelines for the management of patients with metastatic colorectal cancer. Ann. Oncol. 2016, 27, 1386-1422, doi:10.1093/annonc/mdw235.

82. Finn, R.S.; Ryoo, B.Y.; Merle, P.; Kudo, M.; Bouattour, M.; Lim, H.Y.; Breder, V.; Edeline, J.; Chao, Y.; Ogasawara, S., et al. Pembrolizumab As Second-Line Therapy in Patients With Advanced Hepatocellular Carcinoma in KEYNOTE-240: A Randomized, Double-Blind, Phase III Trial. J. Clin. Oncol. 2020, 38, 193202, doi:10.1200/JCO.19.01307.

83. Patel, A.; Sun, W. Ziv-aflibercept in metastatic colorectal cancer. Biologics 2014, 8, 13-25, doi:10.2147/BTT.S39360.

84. Tang, P.A.; Moore, M.J. Aflibercept in the treatment of patients with metastatic colorectal cancer: Latest findings and interpretations. Therap. Adv. Gastroenterol. 2013, 6, 459-473, doi:10.1177/1756283X13502637.

85. Sitohy, B.; Nagy, J.A.; Dvorak, H.F. Anti-VEGF/VEGFR therapy for cancer: Reassessing the target. Cancer Res. 2012, 72, 1909-1914, doi:10.1158/0008-5472.CAN-11-3406.

86. Kadenhe-Chiweshe, A.; Papa, J.; McCrudden, K.W.; Frischer, J.; Bae, J.O.; Huang, J.; Fisher, J.; Lefkowitch, J.H.; Feirt, N.; Rudge, J.; et al. Sustained VEGF blockade results in microenvironmental sequestration of VEGF by tumors and persistent VEGF receptor-2 activation. Mol. Cancer Res. 2008, 6, 1-9, doi:10.1158/15417786.MCR-07-0101.

87. Ferrara, N. Role of myeloid cells in vascular endothelial growth factor-independent tumor angiogenesis. Curr. Opin. Hematol. 2010, 17, 219-224, doi:10.1097/MOH.0b013e3283386660.

88. Abdalla, A.M.E.; Xiao, L.; Ullah, M.W.; Yu, M.; Ouyang, C.; Yang, G. Current Challenges of Cancer Antiangiogenic Therapy and the Promise of Nanotherapeutics. Theranostics 2018, 8, 533-548, doi:10.7150/thno.21674.

89. Ribatti, D. Mast cells and macrophages exert beneficial and detrimental effects on tumor progression and angiogenesis. Immunol. Lett. 2013, 152, 83-88, doi:10.1016/j.imlet.2013.05.003.

90. Raffaghello, L.; Vacca, A.; Pistoia, V.; Ribatti, D. Cancer associated fibroblasts in hematological malignancies. Oncotarget 2015, 6, 2589-2603, doi:10.18632/oncotarget.2661.

91. De Palma, M.; Venneri, M.A.; Galli, R.; Sergi Sergi, L.; Politi, L.S.; Sampaolesi, M.; Naldini, L. Tie2 identifies a hematopoietic lineage of proangiogenic monocytes required for tumor vessel formation and a mesenchymal population of pericyte progenitors. Cancer Cell 2005, 8, 211-226, doi:10.1016/j.ccr.2005.08.002.

92. Shojaei, F.; Wu, X.; Malik, A.K.; Zhong, C.; Baldwin, M.E.; Schanz, S.; Fuh, G.; Gerber, H.P.; Ferrara, N. Tumor refractoriness to anti-VEGF treatment is mediated by CD11b+Gr1+ myeloid cells. Nat. Biotechnol. 2007, 25, 911-920, doi:10.1038/nbt1323.

93. Azam, F.; Mehta, S.; Harris, A.L. Mechanisms of resistance to antiangiogenesis therapy. Eur. J. Cancer 2010, 46, 1323-1332, doi:10.1016/j.ejca.2010.02.020.

94. Casanovas, O.; Hicklin, D.J.; Bergers, G.; Hanahan, D. Drug resistance by evasion of antiangiogenic targeting of VEGF signaling in late-stage pancreatic islet tumors. Cancer Cell 2005, 8, 299-309, doi:10.1016/j.ccr.2005.09.005.

95. Huang, D.; Ding, Y.; Zhou, M.; Rini, B.I.; Petillo, D.; Qian, C.N.; Kahnoski, R.; Futreal, P.A.; Furge, K.A.; Teh, B.T. Interleukin-8 mediates resistance to antiangiogenic agent sunitinib in renal cell carcinoma. Cancer Res. 2010, 70, 1063-1071, doi:10.1158/0008-5472.CAN-09-3965.

96. Chung, A.S.; Wu, X.; Zhuang, G.; Ngu, H.; Kasman, I.; Zhang, J.; Vernes, J.M.; Jiang, Z.; Meng, Y.G.; Peale, F.V.; et al. An interleukin-17-mediated paracrine network promotes tumor resistance to anti-angiogenic therapy. Nat. Med. 2013, 19, 1114-1123, doi:10.1038/nm.3291.

97. Rigamonti, N.; Kadioglu, E.; Keklikoglou, I.; Wyser Rmili, C.; Leow, C.C.; De Palma, M. Role of angiopoietin-2 in adaptive tumor resistance to VEGF signaling blockade. Cell Rep. 2014, 8, 696-706, doi:10.1016/j.celrep.2014.06.059.

98. Keunen, O.; Johansson, M.; Oudin, A.; Sanzey, M.; Rahim, S.A.; Fack, F.; Thorsen, F.; Taxt, T.; Bartos, M.; Jirik, R.; et al. Anti-VEGF treatment reduces blood supply and increases tumor cell invasion in glioblastoma. Proc. Natl. Acad. Sci. USA 2011, 108, 3749-3754, doi:10.1073/pnas.1014480108.

99. Leenders, W.P.; Kusters, B.; Verrijp, K.; Maass, C.; Wesseling, P.; Heerschap, A.; Ruiter, D.; Ryan, A.; de Waal, R. Antiangiogenic therapy of cerebral melanoma metastases results in sustained tumor progression via vessel co-option. Clin. Cancer Res. 2004, 10, 6222-6230, doi:10.1158/1078-0432.CCR-04-0823.

100. Rossi, D.; Hermanowicz, M.; Serment, G.; Khouzami, A.; Bretheau, D.; Ducassou, J. Urethral diverticula in women. Apropos of 7 cases. Ann. Urol. 1989, 23, 352-353. 
101. Navis, A.C.; Bourgonje, A.; Wesseling, P.; Wright, A.; Hendriks, W.; Verrijp, K.; van der Laak, J.A.; Heerschap, A.; Leenders, W.P. Effects of dual targeting of tumor cells and stroma in human glioblastoma xenografts with a tyrosine kinase inhibitor against c-MET and VEGFR2. PLoS ONE 2013, 8, 58262, doi:10.1371/journal.pone.0058262.

102. Kunkel, P.; Ulbricht, U.; Bohlen, P.; Brockmann, M.A.; Fillbrandt, R.; Stavrou, D.; Westphal, M.; Lamszus, $\mathrm{K}$. Inhibition of glioma angiogenesis and growth in vivo by systemic treatment with a monoclonal antibody against vascular endothelial growth factor receptor-2. Cancer Res. 2001, 61, 6624-6628.

103. Madar-Balakirski, N.; Tempel-Brami, C.; Kalchenko, V.; Brenner, O.; Varon, D.; Scherz, A.; Salomon, Y. Permanent occlusion of feeding arteries and draining veins in solid mouse tumors by vascular targeted photodynamic therapy (VTP) with Tookad. PLoS ONE 2010, 5, 10282, doi:10.1371/journal.pone.0010282.

104. Mohajeri, A.; Sanaei, S.; Kiafar, F.; Fattahi, A.; Khalili, M.; Zarghami, N. The Challenges of Recombinant Endostatin in Clinical Application: Focus on the Different Expression Systems and Molecular Bioengineering. Adv. Pharm. Bull 2017, 7, 21-34, doi:10.15171/apb.2017.004.

105. Allen, R.T.; Cluck, M.W.; Agrawal, D.K. Mechanisms controlling cellular suicide: Role of Bcl-2 and caspases. Cell Mol. Life Sci. 1998, 54, 427-445, doi:10.1007/s000180050171.

106. Qiu, B.; Ji, M.; Song, X.; Zhu, Y.; Wang, Z.; Zhang, X.; Wu, S.; Chen, H.; Mei, L.; Zheng, Y. Co-delivery of docetaxel and endostatin by a biodegradable nanoparticle for the synergistic treatment of cervical cancer. Nanoscale Res. Lett. 2012, 7, 666, doi:10.1186/1556-276X-7-666.

107. Mohajeri, A.; Pilehvar-Soltanahmadi, Y.; Pourhassan-Moghaddam, M.; Abdolalizadeh, J.; Karimi, P.; Zarghami, N. Cloning and Expression of Recombinant Human Endostatin in Periplasm of Escherichia coli Expression System. Adv. Pharm. Bull. 2016, 6, 187-194, doi:10.15171/apb.2016.026.

108. Boehm, T.; Folkman, J.; Browder, T.; O’Reilly, M.S. Antiangiogenic therapy of experimental cancer does not induce acquired drug resistance. Nature 1997, 390, 404-407, doi:10.1038/37126.

109. Luo, H.; Xu, M.; Zhu, X.; Zhao, J.; Man, S.; Zhang, H. Lung cancer cellular apoptosis induced by recombinant human endostatin gold nanoshell-mediated near-infrared thermal therapy. Int. J. Clin. Exp. Med. 2015, 8, 8758-8766.

110. Danafar, H.; Davaran, S.; Rostamizadeh, K.; Valizadeh, H.; Hamidi, M. Biodegradable m-PEG/PCL CoreShell Micelles: Preparation and Characterization as a Sustained Release Formulation for Curcumin. Adv. Pharm. Bull. 2014, 4, 501-510, doi:10.5681/apb.2014.074.

111. Jiang, L.P.; Zou, C.; Yuan, X.; Luo, W.; Wen, Y.; Chen, Y. N-terminal modification increases the stability of the recombinant human endostatin in vitro. Biotechnol. Appl. Biochem. 2009, 54, 113-120, doi:10.1042/BA20090063.

112. Chen, W.; Hu, S. Suitable carriers for encapsulation and distribution of endostar: Comparison of endostarloaded particulate carriers. Int. J. Nanomed. 2011, 6, 1535-1541, doi:10.2147/IJN.S21881.

113. Hu, S.; Zhang, Y. Endostar-loaded PEG-PLGA nanoparticles: In vitro and in vivo evaluation. Int. J. Nanomed. 2010, 5, 1039-1048, doi:10.2147/IJN.S14753.

114. Sennino, B.; Ishiguro-Oonuma, T.; Wei, Y.; Naylor, R.M.; Williamson, C.W.; Bhagwandin, V.; Tabruyn, S.P.; You, W.K.; Chapman, H.A.; Christensen, J.G.; et al. Suppression of tumor invasion and metastasis by concurrent inhibition of c-Met and VEGF signaling in pancreatic neuroendocrine tumors. Cancer Discov. 2012, 2, 270-287, doi:10.1158/2159-8290.CD-11-0240.

115. Fredrickson, J.; Serkova, N.J.; Wyatt, S.K.; Carano, R.A.; Pirzkall, A.; Rhee, I.; Rosen, L.S.; Bessudo, A.; Weekes, C.; de Crespigny, A. Clinical translation of ferumoxytol-based vessel size imaging (VSI): Feasibility in a phase I oncology clinical trial population. Magn. Reson. Med. 2017, 77, 814-825, doi:10.1002/mrm.26167.

116. Cortes-Santiago, N.; Hossain, M.B.; Gabrusiewicz, K.; Fan, X.; Gumin, J.; Marini, F.C.; Alonso, M.M.; Lang, F.; Yung, W.K.; Fueyo, J.; et al. Soluble Tie2 overrides the heightened invasion induced by anti-angiogenesis therapies in gliomas. Oncotarget 2016, 7, 16146-16157, doi:10.18632/oncotarget.7550.

117. Koh, Y.J.; Kim, H.Z.; Hwang, S.I.; Lee, J.E.; Oh, N.; Jung, K.; Kim, M.; Kim, K.E.; Kim, H.; Lim, N.K.; et al. Double antiangiogenic protein, DAAP, targeting VEGF-A and angiopoietins in tumor angiogenesis, metastasis, and vascular leakage. Cancer Cell 2010, 18, 171-184, doi:10.1016/j.ccr.2010.07.001.

118. Reardon, D.A.; Lassman, A.B.; Schiff, D.; Yunus, S.A.; Gerstner, E.R.; Cloughesy, T.F.; Lee, E.Q.; Gaffey, S.C.; Barrs, J.; Bruno, J.; et al. Phase 2 and biomarker study of trebananib, an angiopoietin-blocking peptibody, with and without bevacizumab for patients with recurrent glioblastoma. Cancer 2018, 124, 14381448, doi:10.1002/cncr.31172. 